\title{
Use of mathematical software for calculating the pointing angle of laser diode
}

Suganda Jutamulia

Suganda Jutamulia, "Use of mathematical software for calculating the pointing angle of laser diode," Proc. SPIE 9663, Eighth International Topical Meeting on Education and Training in Optics and Photonics, 966327 (6 October 2003); doi: $10.1117 / 12.2208505$

SPIE Event: Eighth International Topical Meeting on Education and Training in Optics and Photonics, 2003, Tucson, Arizona, United States 


\title{
Use of mathematical software for calculating the pointing angle of laser diode
}

\author{
Suganda Jutamulia \\ Department of Optical and Photonic Engineering, University of Northern California, 1304 Southpoint Blvd., Suite 220, Petaluma, CA 94954 \\ suganda.j@osa.org
}

\begin{abstract}
A practical method was developed by a production engineer and a technician to measure the pointing angle of laser diode using a circular aperture. The method provided qualitative measurement only. A theoretical analysis using a mathematical software such as Mathcad shows that the method can provide quantitative measurement as well.

(C) 2003 Optical Society of America

OSIS codes: (000.2060) Education; (140.2020) Diode lasers; (999.9999) Software
\end{abstract}

A production engineer (BS degree) and a technician (no degree) developed a practical method for measuring the pointing angle of laser diode before the laser diode is coupled with a single mode fiber. First, the total power of the laser diode (assuming $\mathrm{A} \mathrm{mW}$ ) is measured before the laser diode is fixed in the fixture. After the laser diode is fixed in the fixture, a small circular aperture (smaller than the beam waist) is centered at the mechanical axis of the fixture. The power of light passing through the aperture (assuming B mW) is measured as shown in Fig. 1. The pointing angle can be represented by the value of $\mathrm{B} / \mathrm{A}$. The larger is the pointing angle, the smaller is $\mathrm{B} / \mathrm{A}$. After the aperture is removed, the light is focused into a single mode fiber at the mechanical axis using proper optics. The coupling efficiency is defined as $\mathrm{C} / \mathrm{A}$, where $\mathrm{C}$ is the measured output power (in $\mathrm{mW}$ ) from the single mode fiber. The effect of the pointing angle of laser diode on the coupling efficiency is shown in the table of C/A versus B/A.

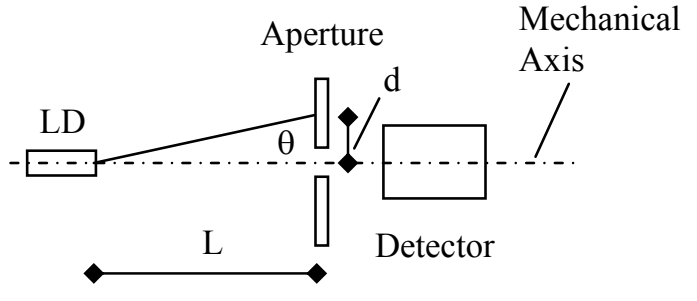

Fig. 1. Measurement setup, $\theta$ : pointing angle.

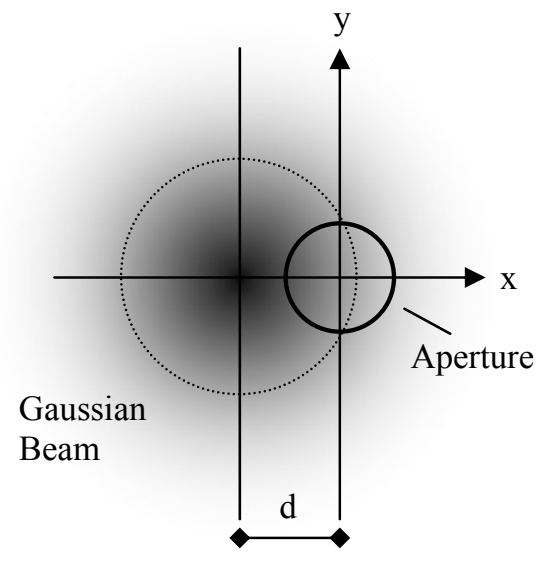

Fig. 2. Positions of laser beam and aperture on aperture plane.

The power of light after passing through the aperture as a function of d (see Figs. 1 and 2) can be calculated, provided that the laser diode beam has been corrected to a circular Gaussian beam [1]. The Gaussian intensity is $\mathrm{I}(\mathrm{x}, \mathrm{y})=\mathrm{I}_{0} \exp \left\{-\left[2(\mathrm{x}+\mathrm{d})^{2}+2 \mathrm{y}^{2}\right] / \alpha^{2}\right\}$, where $\alpha$ is the beam waist, and $\mathrm{I}_{0}=2 \mathrm{~A} / \pi \alpha^{2}$ (remember $\mathrm{A}$ is the total power). The power $B=P(d)=2_{x=-a} \int_{y=0}^{x=a} \int^{y=b} I(x, y) d y d x$, where $a$ is the aperture radius, and $b=\sqrt{ }\left(a^{2}-x^{2}\right)$. Although $B$ or $\mathrm{P}(\mathrm{d})$ cannot be derived analytically, it can be calculated and plotted using a mathematical software such as Mathcad. Therefore, we can calculate the pointing angle $\theta$ from the value B/A.

In conclusion, we have shown how to improve a practical qualitative method developed by an engineer and a technician in a real production facility to an academic quantitative method using a theoretical analysis and a mathematical software such as Mathcad. This will be a good teaching material in the class.

\section{Reference}

[1] S. Jutamulia, "Correction of laser diode beam using microlens optics," Optical Memory and Neural Networks, 10, 113-116 (2001). 